\title{
REGIÓN Y NACIÓN. RELACIONES VECINALES, HISTORIA E INTEGRACIÓN. DESAFÍOS PENDIENTES Y TAREAS INCONCLUSAS
}

\author{
REGION AND NATION: NEIGHBOUR RELATIONS, HISTORY AND \\ INTEGRATION. UNSOLVED CHALLENGES AND UNCOMPLETED TASKS
}

\author{
Eduardo Cavieres F.
}

\begin{abstract}
El trabajo aborda desde la perspectiva de la construcción histórica el aporte que ella ha realizado al desarrollo de la idea de nación e identidad nacional en los países latinoamericanos, con acento en Chile y Perú. En este contexto es pertinente un análisis de los efectos que tiene la producción historiográfica y las historias nacionales, nacidas como base fundante de los Estados latinoamericanos en el siglo XIX, en las relaciones bilaterales y la integración regional entre Chile y Perú en la actualidad.

Palabras claves: Nación, integración, región, Estado, identidad nacional.
\end{abstract}

This paper discusses from the perspective of historical construction the contribution that it made by itself to the development of the idea of nation and national identity in Latin American states, with special emphasis on Chile and Peru.

Moreover, I analyze the effects that the historigrafical development and national histories, born as the foundational bases of the Latin American states during the 19th century, have on bilateral relations and regional integration between Chile and Peru at present. Key words: Nation, integration, region, state, national identity.

\section{El problema en general}

La segunda mitad del siglo XIX conjugó una serie de elementos y circunstancias que permitieron a la mayoría de los nuevos Estados latinoamericanos entrar en una fase de consolidación y modernización basándose en principios del crecimiento económico y del liberalismo. Fue época de logros y cambios importantes, pero en sus efectos de largo plazo se evidenciaron costos sociales elevados y la no consideración de un proyecto nacional que incluyera a la mayoría de los sectores participantes. En el discurso se buscó la unidad nacional, pero en la práctica ello estuvo lejos de ser una preocupación real de los grupos dirigentes. Para ir configurando las definitivas identidades nacionales, con diversos grados de avances y dificultades, los Estados navegaron en aguas poco tranquilas y a veces muy turbulentas.

Por una parte, desde lo económico, las divergencias entre ideas proteccionistas y liberales llevaron rápidamente a valorizar espacios territoriales, antes poco significados, a objeto de beneficiarse con la participación en los mercados noratlánticos y particularmente en las áreas lideradas por Inglaterra. Las luces de la ilustración portadas por los gobiernos liberales al proyectarse en dirección de los nuevos
Estados, llevaron a disputas de carácter geopolítico y de relaciones económicas internacionales que terminaron en graves disputas territoriales y en guerras propiamente tales.

Se trataba de una época de definiciones respecto a la maduración del Estado nacional y de la construcción de identidades nacionales. En forma paralela a lo que sucedía en la propia Europa, en América Latina el proceso contuvo similares contenidos y, entre ellos, las razones patrióticas y la diferenciación respecto de los otros jugaron un papel importante para legitimar las acciones y decisiones tomadas por los grupos dirigentes. Efectivamente, podemos hacer una importante analogía con los desarrollos descritos por Hobsbawm y otros a propósito de estos procesos nacionalistas tan concretamente característicos de la segunda mitad del siglo XIX (Hobabawm e Ranger 2002).

En estos contextos, las guerras entre Estados de la segunda mitad del siglo XIX aceptan lecturas diferentes: una, de contenidos nacionales que reflejan virtudes patrióticas, amor y sacrificio hacia y por la patria, profundas convicciones de que la historia se construye a través de actos heroicos, alto sentido del valor militar, etc. Otra, que corresponde a una faz bastante disímil y que se fundamenta en análisis más

\footnotetext{
* Pontificia Universidad Católica de Valparaíso, Valparaíso, Chile. Correo electrónico: ecaviere@ ucv.cl
} 
concretos de los procesos históricos: los conflictos bélicos se fundamentan en conflictos de intereses en donde se conjugan relaciones de poder internos con subordinaciones o interrelaciones con agentes externos. Allí, el valor de la guerra cobra otras interpretaciones. Por cierto, entre ambas posiciones se dan una serie de situaciones intermedias entre las cuales se cuenta la posición de los gobernantes, las circunstancias mediatas e inmediatas, las representaciones culturales existentes respecto de los conceptos Patria y Nación, etc. Seguramente, una parte importante de los soldados que sobrevivieron a las guerras y de aquellos que sacrificaron sus vidas no marcharon pensando en que estaban siendo utilizados en beneficio de intereses ajenos a ellos mismos, sino lo hicieron en la convicción que se trataba de una causa mayor que comprendía la defensa de su territorio, de su hogar y de su familia.

Cuando pensamos nuestras relaciones vecinales, en el caso particular de las historias de Chile, Bolivia y Perú, la situación regional ocupa un lugar predominante, ya que el problema de la Guerra del Pacífico y sus efectos están aún en el centro de nuestras divergencias. Se puede comprender que los discursos sobre la guerra sean de carácter nacional, y que las recreaciones de la misma asuman el mismo carácter, pero el conflicto se descontextualiza y con ello se eluden responsabilidades importantes. La guerra se observa como un problema nacional y nacionalista, dejando de lado el análisis de la economía mundial de la época, de los desarrollos contemporáneos a la segunda revolución industrial, de la revalorización de grandes espacios y de recursos económicos que hasta entonces no tenían gran valor. El discurso nacional sobre la guerra se olvida de la expansión del capitalismo de la época y de la historia regional escenario de la misma, ámbito poco considerado antes de mediados del siglo XIX (Hobsbawm e Ranger 2002).

Las lecturas del conflicto parten manteniendo un nacionalismo a la manera de la segunda mitad del siglo XIX. Entre liberalismos, crecimientos económicos, ajustes territoriales y políticos, se hace más notoria la invención de lo nacional a la manera europea, o según como lo han planteado Anderson o Hobsbawm. Las historias de Chile, Bolivia y el Perú se amalgaman en sus propias miradas de la guerra y en gran parte se reflejan en la misma. La historia se ha convertido en derrota o en victoria y los sentimientos respecto a los otros en orgullos o en resentimientos. La historia se detuvo y no ha sido capaz de reconstruirse a partir de nuevos desarrollos o entendimientos. A comienzos del siglo XX, en Europa (lo relatan también Hobsbawm o Gellner), las naciones entraron en una fase de nacionalismo cultural que aceptan su pasado y los efectos de la Primera Guerra Mundial, pero que reconocen que quienes formaron en los ejércitos nacionales fueron en gran parte los excluidos y marginados. En América Latina, y en particular en nuestros países, el relato de los dramáticos acontecimientos de la Guerra del Pacífico se transformó en parte importante de los contenidos del nacionalismo, pero también sirvió para que los excluidos lo siguieran siendo. La guerra permitió explicar las faltas de transformaciones sociales más sustantivas al interior de cada una de las sociedades.

Detrás de estas situaciones, la escuela aparece como un ámbito extraordinariamente importante por cumplir con la tarea tan necesaria de formar a los reales ciudadanos del futuro, sabedores de las experiencias del pasado, pero con adecuados conocimientos del mundo en que viven y con criterios fundamentados en el respeto de sí mismos y de los otros. En esto, la historia sigue teniendo un rol fundamental, el de formar para la vida, pero también el de introducirnos en la vida. En lo que respecta al conocimiento de los otros, muy especialmente al de nuestros vecinos, como nos dice Marc Ferro, "No nos engañemos: la imagen que tenemos de otros pueblos, y hasta de nosotros mismos, está asociada a la historia tal como se nos contó cuando éramos niños. Ella deja su huella en nosotros para toda la existencia" (Ferro 1995:9).

A pesar de que la influencia de la escuela es de solo una relativa importancia en la formación de imágenes históricas sobre los grandes sucesos del pasado nacional, no por ello deja de ser un foco central de atención en las preocupaciones que nos asisten cuando pensamos lo que nos sucede con nuestros vecinos inmediatos. Primero, la escuela sigue teniendo importancia; segundo, ¿y qué hacemos con la historia? Seamos realistas: en primer lugar, a cada uno nos gusta y respetamos nuestra propia historia; en segundo lugar, a la mayoría de los historiadores nos interesa el pasado y muchos de nosotros pensamos en que la memoria larga nos es más útil que las puras miradas cortas sobre el acontecer más inmediato; en tercer lugar, no dudamos ni negamos de que la historia nos sirve para reconocer nuestras huellas y nuestras identificaciones; en cuarto lugar, personalmente me inclino a que si 
en la educación básica y en la educación media se enseña historia, simplemente que sea historia y no una simplificación de contenidos mezclados en el ambiguo término de mundo social. No obstante, todo lo anterior no significa pensar en que exista una sola y muy determinada historia y tampoco que exista un solo tiempo, lineal, y siempre progresivo en una sola dirección. Por ello, el asunto de qué enseñar no se transforma en un impedimento cuando se trata de buscar mejores relaciones con otras historias en el presente sin que ello signifique esquivar la memoria histórica del pasado.

El mismo Ferro reflexiona sobre el particular al referirse a que siempre es preciso conocer o reencontrar nuestras huellas y que esto es un viaje en el espacio y en el tiempo. El pasado no es el mismo para todos, pero su recuerdo se modifica con el tiempo de modo que sus imágenes cambian a medida que se transforman el saber, las ideologías y la propia función de la historia. Aún así, "el pasado de las sociedades es más que nunca uno de los envites de las confrontaciones entre Estados, entre naciones, entre culturas y etnias. Controlar el pasado ayuda a dominar el presente, a legitimar dominaciones e impugnaciones". Agrega que las potencias dominantes (Estados, iglesias, partidos políticos o intereses privados) entregan a todos y a cada uno un pasado uniforme y se pregunta si después, llegado el mañana, ¿qué nación o qué grupo humano podrá todavía controlar su propia historia? (Ferro 1995:9-10).

Entre las diversas construcciones de la memoria, la memoria nacional ocupa un lugar privilegiado en la Historia contemporánea. La consolidación de la idea de Estado Nacional y el surgimiento del nacionalismo como fenómeno sociocultural y político de los siglos XIX y XX se constituyeron en contenidos centrales en la relación Estado-ciudadanía. En términos de los procesos de construcción de realidades nacionales y de sentimientos nacionalistas, los caminos seguidos fueron bastante similares en Europa y América Latina. Los fundamentos del Estado nacional, de la soberanía territorial y de los deberes y derechos del ciudadano no solo necesitaron de nuevas instituciones civiles y militares, sino también de espacios y monumentos consagratorios de momentos relevantes de la vida civil, de rituales y símbolos, y de galerías de héroes forjadores de la patria y defensores de esta en momentos de conflictos.

Los avances actuales logrados en torno a políticas de integración entre Estados es algo positivo y deseable, pero sus desarrollos no son casuísticos ni deben ser circunstanciales. La apelación a la historia parece siempre necesaria, especialmente dado que en el pasado las relaciones institucionales han sufrido más de algún inconveniente y han mostrado diferencias de tal grado que no solo han motivado actitudes sociales de confrontación sino que además han llegado a comprometer distorsionadamente el normal nivel de las relaciones de base existentes entre las sociedades que representan.

Nuevamente el conocimiento de la historia, y las formas de transmisión de la misma son de fundamental importancia. De hecho, debe tenerse en cuenta que al tiempo de surgir los procesos de emancipación, en medio de procesos de desintegración de espacios regionales coloniales como consecuencia de las medidas administrativas borbónicas que intentaban recuperar la verticalidad del poder, los Estados nacionales se constituyeron sobre espacios que estaban buscando sus propios procesos de recomposición y con readecuaciones de sus grupos dirigentes a las nuevas condiciones existentes. Las regiones siguieron siendo importantes, pero, por cierto, esos nuevos Estados las reacomodaron y les dieron nuevas significaciones al incorporarlas dentro de los ahora espacios nacionales. A lo largo del siglo XIX, los Estados no solo se manifestaron respecto de su constitución política, sino también lo debieron hacer en términos territoriales y ambos requerimientos no siempre fueron coincidentes temporalmente. Así como hubo espacios valorizados y considerados de forma inmediata, hubo otros que solo en el tiempo merecieron atención de los gobiernos centrales (y también desde el exterior) y ello en general desencadenó conflictos como los conocidos. En el siglo XX es obvio que el concepto nacional operó fuertemente sobre lo regional y a ello se debió, en parte, que el pasado de conflictos se mantuviera sin grandes alteraciones.

En los contextos actuales de la globalización, lo que pueden ser buenas o malas relaciones económicas se ve reflejado en conceptos regionales que vuelven a superar lo nacional. Continuamente aparecen nuevos líderes que intentan asociar el concepto de región a lo que consideran su propio pensamiento respecto de lo que debe ser el futuro de América Latina. Se van asumiendo las posibilidades de reconstrucción de relaciones vecinales y regionales, pero no siempre a partir de una historia común, de similitudes de tipo cultural, y de intereses sociales comunes. Nos enfrentamos a un doble lenguaje, 
que por lo general no proviene de forma o manera inmediata de las propias sociedades, sino de los medios de comunicación, de los empresarios, etc. Por una parte, nos encontramos con un lenguaje de acercamiento, de reconstrucción de lo regional; por otra, prevalecen las políticas tendientes a ver cómo insertamos estos espacios lo más directamente al mundo globalizado, a través de acuerdos de libre comercio con economías mayores, pero lejanas, sin ver a nuestro alrededor. Se intenta aplicar en América Latina la solución de algunos problemas al modo europeo, pero como mala copia europea, asignando la mayor parte de los esfuerzos solo a lo económico. No siempre se toma en cuenta lo que han sido y deben ser estas regiones, sino en cómo pueden actuar dentro de buenas o malas opciones económicas. Cuando los negocios andan bien, la región y los convenios funcionan, pero cuando la economía no anda bien, inmediatamente lo que se había avanzado vuelve al estado anterior. Las competencias económicas se establecen respecto del exterior, dejando de lado las posibilidades de reconstrucción de relaciones vecinales regionales a partir de una historia y de intereses y problemas en común (Cavieres 2007:9-14).

\section{El siglo XIX en cuanto a formador de una mirada histórica e historiográfica}

Mirados esos tiempos más en profundidad, no podemos soslayar las bases de una construcción de la historia que se terminó de transformar en la historia misma. En primer lugar, la historia de los Estados nacionales, historias que efectivamente existen en cuanto responden, o tratan de responder, a sus propias formas de dar respuesta a sus procesos internos o conectados a historias vecinales. Sin embargo, no hay que olvidar ni soslayar la influencia de procesos mayores en los cuales, de igual forma, ellas están insertas y que, la mayoría de las veces, tienen mayores fuerzas y repercusiones de las que creemos. La expansión del capitalismo, y también del imperialismo del siglo XIX siempre están presentes en nuestras memorias historiográficas, pero siempre se tienden a soslayar cuando se trata de manifestar sentimientos divergentes respecto de las culpabilidades de los vecinos y reforzar los argumentos sobre la justicia respecto de las propias decisiones tomadas en contra de ellos. A lo anterior se une en los caracteres de la construcción de las identidades desde y hacia los Estados nacionales durante el mismo período, construcción con sus propias definiciones y sus propias justificaciones dentro de lo que fue el siglo XIX.

En segundo lugar, el problema no es solo de la historia en cuanto a cómo ha venido sucediendo y cómo se ha plasmado en hechos y procesos no siempre positivos. Quizás, más importante, es considerar el cómo la hemos pensado y qué contenidos le hemos otorgado para validar nuestros propios actos, por lo tanto, en forma previa a lo que ha sucedido con ella. En paralelo a la economía, a la política, a los conflictos de intereses, existe también una historia de cómo se construyen las ideas sobre la historia y ella, con luces y sombras, ilumina igualmente el suceder.

En 1996, a partir de las notas de un curso que el historiador Lucien Febvre había dictado en los años académicos 1945-46 y 1947 se publicó en París el libro Honor y Patria, desarrollado a partir de la experiencia y reflexiones del historiador respecto del "desembarco de los aliados en África del Norte y el desgarramiento de unos hombres, de una nación, en ese cruce de caminos" (Febvre 1999:16). Dichos manuscritos, ordenados por el mismo Febvre en dos momentos, 1947 y 1955, quedaron olvidados por dos décadas hasta ser recuperados por François Furet en 1987.

Según los argumentos de Febvre, la patria es palabra del siglo XVI y sería falso que hubiese sido utilizada tan anteriormente como por Juana de Arco, quien más bien habló de país. Apareció entre 1540 y 1550. Rabelais la usó en 1546 y siguiendo a algunos otros historiadores, Febvre toma la acepción de ser una nueva manera de amar a Francia, una manera de amar como los atenienses amaron a Atenas y los romanos a Roma. Ese patriotismo antiguo se incorporó a un patriotismo moderno resultando el patriotismo de la Revolución, a la vez nacional, por los recuerdos nacionales y por la transmisión de los mismos. Sin embargo, el patriotismo del siglo XVI fue profundamente $\mathrm{y}$ antes que nada un patriotismo rural y local: evocaba la tierra, los muertos, la tierra: ese gran osario de los muertos.

La nación es más bien una realidad psicológica. Responde a la noción de articulación: no está hecha de individuos, está hecha de grupos (familias, oficios, escuelas, iglesias) que ella unifica y subordina a tareas comunes: "La Nación es la toma de conciencia de una historia que reacciona de modo perpetuo a un ideal, de un ideal que reacciona de modo perpetuo a la historia. La historia vivida en común determina 
la toma de conciencia. Y esta toma de conciencia marca la representación de la historia, el sentido de la historia, el curso mismo de la historia. La Nación es, a la vez, un hecho padecido y un hecho deseado, de ahí su fuerza" (Febvre 1999:1596).

Es a fines del siglo XVIII cuando el concepto de nacional se impone: industria nacional, trabajo nacional, prosperidad nacional, manufacturas nacionales, educación nacional, producción nacional, espíritu nacional, política nacional, Asamblea Nacional. Hegel escribió: "Tienen suerte, ustedes los franceses: son una nación” (Febvre 1999:169). La Revolución francesa terminó de precisar los contenidos de los conceptos al entregar nuevos significados. Desde que comenzó la lucha entre los privilegiados y los otros, los conceptos de Patria y Honor comenzaron a oponerse de un modo muy natural: los partidarios de la Asamblea, y luego de la República fueron los patriotas. Los otros reivindicaron para sí el monopolio del honor. El divorcio fue claro: "El honor está en un campo, la patria está en el otro" (Febvre 1999:179). Sobre ellos, la Nación.

Sobre estos contenidos y nuevas construcciones de la historia, Marc Ferro se ha distinguido respecto del cómo entenderla y cómo enseñarla y se ha detenido en la larga duración de relaciones (o desrelaciones) entre Francia y Alemania, como el mejor de los ejemplos para observar de que los conflictos pueden superarse a partir del encuentro de objetivos comunes. Desde la Guerra de los Treinta Años en adelante (1618-1848), esas sociedades, en otros contextos políticos y de definiciones de identidad, se convirtieron en enemigos hereditarios, aún cuando por entonces los alemanes contaban muy poco, mientras que la lucha contra España o Inglaterra se antojaba prioritaria para Francia. Ignorar y despreciar a Alemania vino a sumarse así el resentimiento de ella. Con la Revolución de 1789, la situación algo mejora, particularmente por la simpatía mutua que sentían los filósofos ilustrados de ambos países, los de las Lumiéres y los de la Aufklärung: Klopstock, Hörderlin, Grima, d'Holbach, Diderot, pero rápidamente se esfuma con Napoleón y la creación en 1806 de la Confederación del Rin (mi confederación, como decía Napoleón), la cual no tarda en extenderse hasta el Elba llegando a ciento treinta departamentos y al dominio de Francia sobre Westfalia y Baviera integradas a su territorio. Alemania se sintió humillada, despojada: Fichte la incita al levantamiento... La unificación del país, imperativo categórico, se lleva a cabo cuando Prusia la incluye en su programa y Bismarck cosecha sucesivas victorias sobre Austria-Hungría y Francia en 1866 y 1871 . Recupera las provincias, pero su resentimiento resucita cuando Francia recupera Alsacia-Lorena en 1918. El programa alemán de 1914 preveía la recuperación de Luxemburgo, del Franco Condado y de una parte de Borgoña, con el fin de que el Reich recobrara las fronteras del Santo Imperio en tiempos de Segismundo: "Esos objetivos son precisamente los de Hitler y del nacionalsocialismo que ya entonces, en el momento de su victoria sobre la III República francesa, recupera (nuevamente) Alsacia y Lorena, a la espera de más, cuando el Reich haya vencido a Inglaterra y a la URSS. Pero la historia decidió otra cosa" (Ferro 2009:136-138).

En cuanto al resentimiento de los franceses, siguiendo al mismo Ferro, este se manifestó contra Prusia antes de que pasara a ser antialemán. Entre 1740 y 1748, en la guerra de sucesión de Austria, Luis XV se alió con Federico II, el cual lo abandonó una vez anexionada Silesia. En adelante, Federico II apareció en todas las coaliciones en contra de Francia. El resentimiento creció con la ayuda que Prusia prestó a la coalición europea al regreso de la campaña de Rusia. Prusia apareció como una potencia en auge que, junto a Inglaterra, buscaba la ruina de Francia. La envidia alimentó el resentimiento contra el vecino y contra sus escritores, filósofos y artistas: Schiller, Goethe, Hegel, Beethoven, Schumann, Brahms, Mendelssohn y Wagner. Para diferenciarse, Debussy exigía que le llamasen músico francés. Koch competía con Pasteur y la escuela de medicina de París. En 1848, Bismarck denunció la "anarquía francesa" y su diplomacia construyó un obstáculo para Napoleón III y fomentó el síndrome del enemigo hereditario después de la pérdida de Alsacia Lorena y del sitio de París de 1870-1871. Es después de la Primera Guerra que los alemanes tomaron el relevo de los prusianos. Es a ellos, más que a los nazis, que los dirigentes y opinión pública estigmatizaron, a favor o en contra de la colaboración. Sólo los católicos de izquierda (Esprit) y algunos políticos prestaron atención a la distinción, los comunistas hicieron referencia al fascismo. Terminada la Segunda Guerra, los productos de la ocupación y el descubrimiento de los campos de exterminio exacerbaron el resentimiento contra todos los alemanes, nazis y cómplices, militares o civiles (Ferro 2009:138-139). 
A mediados del siglo XX, cuando la historia estaba presente, viva, llena de imágenes de dolor, ira, rabia, odios, de una manera impredecible, curiosa, pero muy positivamente, comenzó la transformación de los significados de la historia. Mucho se ha hablado de las tempranas colaboraciones económicas entre Francia e Inglaterra. Ferro agrega consideraciones culturales y percepciones sociales:

Poco a poco se observa un doble cambio. Mientras que la mayoría de los franceses llevan los estigmas de la ocupación, aquellos que han sido prisioneros - por supuesto no los deportados- tienen una visión más favorable de Alemania, porque no han sido maltratados, sentimiento que el cine expresa en La vaca y el prisionero de Henri Verneuil, con Fernandel (1959), y en El paso del Rin de André Cayatte, con Charles Aznavour (1960). Además, dividido en cuatro (las dos Alemania, Austria y Berlín), el antiguo Reich ya no se percibe como una amenaza, condición que se traslada a los estadounidenses o a los soviéticos: De Gaulle le da el abrazo de la reconciliación a Adenauer, ademán que renovarán Mitterrand y Kohl en Verdún. Por lo demás, gracias al plan Monnet y a Robert Schuman se desarrollan las relaciones económicas entre los dos países, apareciendo cierta complicidad entre los "gestores" a ambos lados del Rin. Finalmente, en Francia cada vez es mayor la tendencia a atribuir a Vichy la responsabilidad de crímenes que durante mucho tiempo se imputaron a los alemanes y solo a ellos (Ferro 2009:139-140).

Sobre toda esa historia, Hobsbawm fue más lejos y dejó una reflexión mirando al futuro. Lo hizo desde el pasado, analizando lo que está sucediendo y pensando en sus proyecciones: "El proceso por el que los campesinos se convirtieron en franceses y los inmigrantes en ciudadanos norteamericanos se ha invertido, y las identidades de los grandes Estados-nación se desmoronan para dejar paso a una identidad colectiva consciente de sí misma, o incluso a identidades privadas a-nacionales de $u b i$ bene ibi patria. A su vez, todo no es sino el reflejo de la pérdida de legitimidad del Estado-nación a ojos de quienes ocupan su territorio, y la reducción de lo que puede exigir a sus ciudadanos. Que los Estados del siglo XXI prefieran librar sus guerras con ejércitos profesionales o incluso con contratistas militares privados no responde únicamente a cuestiones técnicas, sino a que ya no pueden confiar en que los ciudadanos se alisten masivamente para morir por su patria en el campo de batalla. Los hombres y las mujeres pueden aceptar morir (o, mejor dicho, matar) por dinero, o por algo más o menos importante; sin embargo, en las patrias originales de la nación, ya no están dispuestos a morir por el Estado-nación (Hobsbawm 2007:97).

\section{El presente de la historia y las relaciones chileno-peruanas}

Estos últimos son temas complicados, y para muchos lejanos a nuestras propias realidades; pero no por ello deben simplemente ignorarse. Formamos parte de un mundo más global, no solo en términos económicos, sino también en términos de ideas y actitudes. La historia pesa y no se trata de olvidarla, sino más bien de repensarla y adecuarla a nuestros propios tiempos y requerimientos. Esfuerzos existen y, entre otras propuestas, no deben pasar inadvertidas las ideas recientemente vertidas por el Canciller peruano, Rafael Roncagliolo, ante el Consejo Chileno para las Relaciones Internacionales. El Canciller aseguró que Chile y el Perú deben enfrentar conjuntamente los diversos desafíos que se plantean a futuro, impulsando una amplia agenda de trabajo y realizando un esfuerzo para superar las percepciones equívocas de uno y otro lado. Habló de las prioridades por la integración regional y sobre el rol y potencial de América Latina en el escenario global: el crecimiento debe "apuntar a mejorar la competitividad regional y fortalecer las políticas de inclusión social... América Latina no es la más pobre del planeta, pero sí la más desigual y se (la) debe pensar (como) de hoy y no del pasado. Refiriéndose específicamente a las relaciones chileno-peruanas, señaló la necesidad de enfrentar conjuntamente los diversos desafíos a través de una amplia agenda de trabajo y superando las percepciones equívocas de uno y otro. "En el siglo XIX las diferencias se decidían por la fuerza, pero hoy "las rivalidades desaparecen" y de la "integración de la retórica se pasa a la integración de la realidad" (Roncagliolo 2013).

Respecto de consultas sobre el Tratado de 1929 y por qué del diferendo de La Haya, señaló que hay percepciones recíprocas en ambos países: En Chile se aprecia un "irredentismo peruano" y en Lima existe una percepción de que Chile nunca va a dejar de armarse contra Perú. "Contribuir a un buen clima de entendimiento no es solo responsabilidad de los Estados ni solo de las cancillerías. Compromete a todos los sectores de la sociedad": "El diferendo 
con Chile no es un pleito, sino una diferencia, y con ese espíritu estamos trabajando".

$\mathrm{Al}$ recordarse acerca de la relación francoalemana con mención a tres guerras y múltiples desavenencias se subrayó que estas quedaron atrás en beneficio de la unidad y prosperidad de dos pueblos. Roncagliolo aseguró que "no hay ejemplo más transparente que el mencionado" y que Perú aspira a tener con Chile una relación que replique la descrita, recalcando que "no hay enemigos naturales ni hereditarios ni destinos prefijados". Habló de avanzar hacia una "ciudadanía sudamericana". "Empezar por lo que es posible, pero miremos más allá. Esta puede ser la hora, la década, el siglo de América Latina. La crisis es una oportunidad para un gran salto de la región, no para unos países en contra de otros" (Roncagliolo 2013).

Mirando la historia, es un equívoco el que haya que suprimir el pasado para construir el futuro. No se trata de volver a enterrar a los muertos y héroes del pasado. Por el contrario, se trata de comprenderles en sus intenciones y en sus circunstancias. En el presente, se trata de leer la historia en los términos actuales y de significar convenientemente el pasado. Conceptos como honor, patria, nación siguen siendo muy importantes y, por ello, la historia del pasado es también formadora de niveles de identidad que resultan absolutamente válidos y valiosos. Pero los contenidos de la definición también cambian. El siglo XXI no es el siglo XIX, tampoco sus circunstancias. En el presente las relaciones sociales alcanzan significaciones prioritarias en los desarrollos actuales de los Estados nacionales $\mathrm{y}$, con ello, sus requerimientos, sus necesidades, sus proyectos en un mundo cada vez más globalizado hacen imperioso dar respuestas históricas para el siglo XXI: una de ellas es la complementariedad social y la integración cada vez más plena de sociedades que, en conjunto, y no a través de la pura competencia, pueden efectivamente alcanzar los logros necesarios para definitivamente alcanzar esas patrias grandes, solidarias y fraternales que en su momento también los caídos en batalla pensaron para sus hijos y generaciones futuras.

Como lo señalaba el Canciller Roncagliolo no es tarea solo de los gobiernos. No es tarea solo de los empresarios. Es tarea de todos, de intelectuales, de trabajadores, de la educación y de los medios de comunicación social. Es tarea también de los historiadores el darle nuevos sentidos a la historia que se transmite y se enseña y convertirla socio-culturalmente en instrumento de paz y de integración.

\section{Una propuesta académica: las historias binacionales}

Tenemos un problema básico y cada vez más urgente: se debe dar contenido al concepto de América Latina. Existe la idea, pero no la realidad. Los Estados latinoamericanos siguen ligados a sus contextos decimonónicos y sus sentidos de independencia a menudo chocan contra los intereses de los vecinos: unos y otros. ¿cuál será el verdadero camino para reorientar positivamente esta situación? Siempre apelo a Fernand Braudel y a su Identidad de Francia para entender de mejor forma nuestros propios nacionalismos. Para Braudel, el cariño por la propia historia, el cariño por el país al cual se pertenece, no significa necesariamente no tener capacidad para cuestionarse y preguntarse por las propias identidades, que sin perder sus esencias son capaces de ir alcanzando nuevos contenidos a través del tiempo. El cariño por la patria y por la historia menos aún imposibilita tener profundos, positivos y leales sentimientos hacia los vecinos. En muchas ocasiones, las propias autoridades nacionales no se atreven a dar pequeños, pero significativos pasos en pos de una unión más profunda entre nuestros pueblos por temor a ser considerados como traidores a sus propias historias. El problema se sitúa en establecer el nivel en que los gobiernos puedan tomar decisiones sustantivas para reivindicar las historias nacionales en concordancia con los requerimientos históricos actuales. Así lo entendieron los países europeos: La idea central fue que, "Construir Europa es generar un espacio público que puedan compartir los ciudadanos europeos de los distintos Estados miembros... - en que el valor intangible, como la pertenencia al espacio común y a un destino compartido, significaba que - "todos cedemos parte de la soberanía nacional originaria para ponerla en común con los demás... Nada resta a nuestra identidad como ciudadanos de cada uno de nuestros países" (González 2012:25).

El proceso de conformación de la Unión Europea no fue fácil ni rápido. Más aún, se desarrolló cuando los hombres, las ideas y las tragedias de la Segunda Guerra Mundial estaban aún presentes. No se trató de negar la historia inmediata sino más bien de rectificar sus elementos negativos para posesionarla en términos más positivos. 
Considerando todo lo expuesto, el papel de la historia, de los Estados, de la escuela, ¿Cómo contribuir en América Latina a unas lecturas más apropiadas de la historia y de sus historias nacionales? No tenemos una gran historiografía que corresponda efectivamente a los términos y contenidos de América Latina; más bien se trata de obras que recorren Latinoamérica contando cada una de las historias nacionales. Difícil es pensar en construir un relato común en forma global. Desde la Universidad hemos pensado más bien en la perspectiva regional o, mejor aún, en términos vecinales. A partir de ello se originó un programa y sus correspondientes acciones. Se constituyó un grupo de historiadores chilenos y peruanos para escribir una historia común de ambos países, incluyendo el peso de la Guerra del Pacífico. Por cierto hubo escepticismos e incluso actitudes contrarias al proyecto. No obstante ello, los historiadores comprobaron que sí era posible. El resultado, un libro, Chile-Perú, Perú-Chile: 1820-1920... cuya presentación fue realizada por los Rectores de la P. Universidad Católica de Valparaíso y de la Universidad Mayor de San Marcos, Lima. Decían:

La historia comparativa, con referentes más allá del ámbito territorial y social de una nación, como lo aseguran los especialistas, es un signo inequívoco de madurez de una historiografía nacional. Es este género el que ha permitido el desarrollo de las grandes historiografías europeas, como la alemana, francesa, inglesa e italiana del siglo XX, para mencionar solo algunos ejemplos. Por eso el recordado historiador sanmarquino Jorge Basadre no se equivocó al considerar fundamental los análisis comparativos cuando se quiere lograr un mayor nivel de objetividad y profundidad en el conocimiento de la historia de las naciones. Por estas consideraciones, estamos seguros de que la vocación comparativa y los conceptos modernos utilizados como herramientas en la elaboración del presente libro, lo hacen de suma utilidad para que los ciudadanos de Perú y Chile tengan un mejor entendimiento de sus propias historias nacionales (Cavieres e Aljovín 2012).

Como método, el análisis comparativo permite acercarse a lo común. Utilizándose anteriormente, enfatizó mucho más en las diferencias que en los puntos comunes que permiten establecer semejanzas en los desarrollos narrativos de ambos países. En ese sentido, los contenidos del libro buscaron comprender la historia de Chile y el Perú en torno a las problemáticas comunes e intentaron, además, superar la carencia de trabajos recientes que discutieran ambas historias de un modo más concienzudo.

Le siguieron proyectos similares con Bolivia y, posteriormente, con Argentina (Cavieres y Cajías 2008; Cavieres e Cicerchia 2012). No obstante, en lo más cercano y desde la escuela, no es que no hayan existido efectivos proyectos educativos. Están los deseos sociales, faltan los apoyos oficiales. Los Ministerios de Educación no se han atrevido a romper las historias institucionales y oficiales. Entre tantos otros proyectos, profesores de Arica y Tacna fueron capaces de dar contenidos comunes a problemas didácticos comunes relativos a la prehistoria y la historia de la integración regional Tacna-Arica; Análisis y Programas de Historia, Diversidad Cultural y Social; Integración latinoamericana; instituciones actuales y posibilidades futuras. Apoyaron, además, una unidad didáctica presentada por Fanny Barrientos Cruzat para ser desarrollada en ambas ciudades: "Construyendo una visión global de las historias de Chile y el Perú: vinculando mi historia familiar con la historia local, nacional y de América Latina". A falta de recepción y apoyo de las autoridades superiores, allí quedaron los esfuerzos y los entusiasmos ${ }^{1}$. No ha sido lo único. En la misma Arica, analizando la Guerra de 1879, Patricio Rivera ha pensado la integración a través de propuestas concretas respecto de la enseñanza de la historia: contenidos, propuestas y prácticas. Entre sus conclusiones, señala que "El Estado, sus gobiernos y las elites intelectuales han sido los responsables de endosar a las sociedades chilena, peruana y boliviana la carga valórica de la Guerra de 1879, generando invenciones míticas que la sociabilidad popular de los tres países ha generalizado en torno a diferenciaciones de frontera que se han manifestado en prejuicios, exclusiones, discriminaciones y estereotipos" (Rivera 2011:163). Estas acciones de exclusión, señala el autor, se hacen obsoletas en los nuevos escenarios de la globalización y la cooperación internacional. Una nueva orientación de la enseñanza de la historia y de comprensión por el papel actual de la historia es, por tanto, cada vez más necesaria.

\section{Consideraciones finales}

En términos amplios y más generales, en los contextos de nuestras relaciones vecinales, también a lo largo de América Latina, hoy día seguimos 
enfrentados a unos mismos subconscientes colectivos que se exteriorizan en los mismos prejuicios, que se reproducen en las mentes de nuestros niños y de nuestros jóvenes, proyectando las mismas imágenes del pasado. Sus contenidos esenciales siguen respondiendo a estos problemas de larga duración, no resueltos. Nuestro desafío es cómo hacer para que la historia no se siga convirtiendo en carga, y menos aún en un factor que nos lleva únicamente hacia el pasado. La tarea es el cómo lograr que la misma historia nos permita también visualizar el futuro con sinceridad, honestidad y con profundos sentimientos de sensibilidad por nuestros vecinos. Los regionalismos, la historia, los contenidos sociales, son importantes de tomar en cuenta si queremos reencontrarnos más allá de lo puramente económico o inmediato. Ojala nuestros esfuerzos puedan orientarse en ir despejando los caminos del desencuentro y hacer entender a los gobiernos que no basta recordar los hechos del pasado, sino que es igualmente necesario buscar la forma de superar los conflictos y mirar en conjunto hacia el futuro.

A este punto, conviene considerar dos situaciones claves para pensar que podemos manejar adecuadamente nuestro pasado sin por ello traicionar las propias historias e identificaciones nacionales. En primer lugar, lo concerniente a los desarrollos sociales de nuestras sociedades. El mantener a importantes sectores sociales en una situación de atraso, hace más posible que estos sean manipulados con conflictos externos a objeto de minimizar los propios problemas internos. Sociedades más plenamente incorporadas en proyectos sociales tendientes a superar los males del subdesarrollo aún presentes a lo largo de América Latina, serán más respetuosas con sus identificaciones regionales y nacionales y más proclives a reconocer que lo que sucede a otros también forma parte de problemas, tareas y miradas históricas que tienen mucho de común con lo propio.

Lo segundo tiene que ver con las disposiciones y voluntades políticas de los gobernantes para encontrar soluciones que den permanencia en el tiempo a las visitas de buena cortesía, a la firma de documentos de buenas intenciones, a los convenios o acuerdos bilaterales, abiertos o específicos, que, en la mayoría de los casos, aparecen circunstancialmente de acuerdo con requerimientos del momento o a las disposiciones o simpatías producidas entre autoridades de ambos países que, desgraciadamente, desaparecen al mismo tiempo que estas dejan sus cargos o cesan en sus posiciones de poder. Esas buenas intenciones no logran transformarse de una vez en políticas permanentes de Estado que, a partir de diversas acciones, permitan avanzar definitivamente en la búsqueda de relaciones más altruistas entre sociedades que siendo diversas, tienen también mucho de común. La experiencia de la comunidad europea no es necesariamente una situación a replicar íntegramente, pero sí un excelente ejemplo a considerar ${ }^{2}$.

Hemos señalado que a la escuela y a la educación les corresponde un importante papel a jugar en la construcción de una cultura que guíe las relaciones entre los países en forma más solidaria y más decididamente proclive a la paz. La Universidad, como institución de educación superior, no está exenta de asumir sus propias responsabilidades. La búsqueda de eficiencia y mejores productividades no puede soslayar que, entre sus fines, el pensamiento, la reflexión, el desarrollo de ideas, para la cultura, para la sociedad, para la historia, sigue siendo tarea principal y fundamental.

\section{Referencias Citadas}

Cavieres, Eduardo

2007 Historia nacional, nacionalismos, conflictos e integración; en Orietta Ojeda B. (comp.), VI Encuentro de Historiadores, intelectuales y cientistas sociales Bolivia-Chile, Iquique 17-18 octubre 2006; Edit. Universidad Bolivariana, Colección Estudios Regionales, Santiago 2007, Introducción, pp. 9-14. Cavieres, Eduardo y Aljovín, Cristobal (comps.)

2005 Chile-Perú, Perú-Chile: 1820-1880. Desarrollos políticos, económicos y culturales; Pontificia Universidad Católica de Valparaíso, Convenio Andrés Bello, Universidad Mayor de San Marcos; Euval, Valparaíso 2005, Reimpresiones en 2006, 2007 y 2012. Además, edición Fondo Editorial UNMSM, Lima, Perú 2006.
Cavieres, Eduardo y Cajías de la Vega, Fernando (coords.) 2008 Chile-Bolivia, Bolivia-Chile, 1820-1930. Desarrollos políticos, económicos y culturales; Pontificia Universidad Católica de Valparaíso, Universidad Mayor de San Andrés, La Paz; Valparaíso 2008.

Cavieres, Eduardo y Ricardo Cicerchia (coords.) 2012 Chile-Argentina, Argentina-Chile, 1820-2010. Desarrollos políticos, económicos y culturales; PEI*sur- SEPHILA, Pontificia Universidad Católica de Valparaíso, Universidad de Buenos Aires, Valparaíso 2012.

Cavieres, Eduardo

2006 Chile-Perú. La historia y la escuela. Conflictos nacionales, percepciones sociales; Instituto Chileno-francés; 
Pontificia Universidad Católica de Valparaíso, MineducChile, Valparaíso 2006, pp. 102-104 y 115-118.

Galdames Rosas, L. y Díaz Araya, A.

2007 "La construcción de la identidad ariqueña en las primeras décadas del siglo XX”, Revista Diálogo Andino № 29, páginas 19-28, Universidad de Tarapacá, Arica, Chile.

Febvre, Lucien

1999 Honor y Patria [1996], s. XXI, Madrid 1999.

Ferro, Marc

1995 Cómo se cuenta la historia a los niños en el mundo entero; FCE, México1995 ( $1^{\text {a }}$ reimpresión).

González, Felipe

2012 Mi idea de Europa, RBA Libros, Barcelona.

Hobsbwm, Eric y Ranger, Terence (eds.)

2002 La invención de la tradición. Ed. Crítica.
Hobsbawm, Eric

2007 Guerra y paz en el siglo XXI, Crítica, Madrid.

Marc Ferro

2009 El resentimiento en la Historia, Cátedra, Barcelona.

Patricio Rivera Olguín

2011 La guerra de 1879 y la integración: desde la enseñanza de la historia, Imagina, Iquique, Chile.

Proyecto EXPLORA, Comisión Nacional de Ciencia y Tecnología, Chile. 9 febrero 2009

Revista Ercilla, Un camino forzado, No 3, 369. Semana 6-19 abril 2009. Santiago, Chile.

Roncagliolo, Rafael

2013 Canciller peruano, ante el Consejo Chileno para las Relaciones Internacionales, Santiago 25 enero 2013: Aspiro a una relación Chile-Perú como ha sido la franco-germana; El Mercurio, Santiago, 3 febrero 2013, p. D8 Reportajes.

\section{Notas}

1 Ver textos en Eduardo Cavieres, Chile-Perú. La historia y la escuela. Conflictos nacionales, percepciones sociales; Instituto Chileno-francés; P. Universidad Católica de Valparaíso, Mineduc-Chile, Valparaíso 2006, pp. 102-104 y $115-118$.
2 En este trabajo he recogido reflexiones y propuestas publicadas en EXPLORA, CONICYT, 09 febrero 2009 y por Revista Ercilla, Un camino forzado, $\mathrm{N}^{\mathrm{o}} 3,369$, semana 06-19 abril 2009. 